\title{
The Contribution of Information and Communication Technology to Social Inclusion and Exclusion during the Appropriation of Open Educational Resources
}

\author{
Lancelord Siphamandla Mncube ${ }^{1}$, Maureen Tanner ${ }^{2} \&$ Wallace Chigona ${ }^{2}$ \\ ${ }^{1}$ Department of Information Science, University of South Africa, Pretoria, South Africa \\ ${ }^{2}$ School of Information Technology, University of Cape Town, Cape Town, South Africa \\ Correspondence: Lancelord Siphamandla Mncube, Department of Information Science, University of South Africa, \\ Pretoria, South Africa.
}

Received: August 29, 2021

Accepted: October 25, 2021

Online Published: November 2, 2021

doi:10.5430/ijhe.v10n6p245

URL: https://doi.org/10.5430/ijhe.v10n6p245

\begin{abstract}
The information and communication technology (ICT) comprehends with the adoption and the development of open educational resources (OER) in the educational spheres. The vast existing body of knowledge portrays several positive aspects of ICT, as it is an enabler in various domains. Hence, the combination of ICT and OER negative aspects have been, as yet, under-investigated. This study aimed to investigate both the social inclusion and the social exclusion of ICT with users appropriating of OER in open distance e-learning (ODeL) institutions. The qualitative approach was used to interpret the inclusion and exclusion factors concerned. The Model of Technology Appropriation was applied as a main theoretical underpinning of the study. The study findings show that ICT has both positive and negative impacts on the appropriation of OER. The various impacts are mostly recognisable in those developing countries where inequalities still exist, as some of the findings postulate that the innovation that is enabled through the utilisation of ICT tends to favour a select minority of rich people. For many students, ICT continues to perpetuate social exclusion. ICT innovation, including OER, has yet to fully support societal needs. Instead, it continues to promote the agendas of the global north. The study recommends the development of initiatives to close the current gaps which contribute to the social exclusion. For instance, the installation of fibre optic in most deprived townships and villages can assist in eliminating inequalities associated with ICT infrastructure.
\end{abstract}

Keywords: information and communication technology, appropriation, social inclusion, social exclusion, open educational resources, open distance e-learning institution

\section{Introduction}

Information and communication technology (ICT), which plays a significant role in higher education, has contributed to the quality of teaching, learning and research activities (Noor-Ul-Amin, 2013). Moreover, the development of ICT has caused a paradigm shift, with it having changed existing student learning approaches (Al-Rahmi, Alzahrani, Yahaya, Alalwan \& Kamin, 2020). Such change has been influenced by the introduction of computers, the internet, mobile phones, tablets and other peripheral devices to the academic domain (Brown \& Green, 2009).

The increased use of ICT in the higher education context has facilitated the emergence of open educational resources (OER) (Weller, 2014). OER can be defined as digitised resources that are offered freely and openly to academics for use and reuse in their teaching and research (Todorinova \& Wilkinson, 2020). Although OER are relatively recent developments in the context of ICT-enhanced learning, they have already had an impact on the teaching and learning practices of higher education institutions globally (Bates, 2015). Therefore, studying the appropriation of OER, as supported by ICT in the context of higher education, can be seen to be important. 'Appropriation' is a term that is used to describe the adoption, development and use of an artefact (Silverstone \& Hirsch, 1992; Carroll, Howard, Peck \& Murphy, 2002). The appropriation of OER has the potential to advance teaching, learning and research, especially in developing countries.

Given that the use of OER for educational purposes is supported by ICT (Weller, 2014), they have come to be seen as contributing to social inclusion (Tang \& Bao, 2020), yet little is known regarding OER' contribution to social exclusion. In the light of such uncertainty, the current study avoids treating ICT as a different entity to OER, because 
the assumption is that ICT can contribute to both social inclusion and exclusion in the context of developing countries. Therefore, the current study sought to answer the following research question:

\section{- How does ICT contribute to social inclusion and exclusion during the appropriation of OER?}

ICT has been documented as playing a role in a higher education institution for different reasons (Bala, 2018; Khan, 2020). A vast amount of literature seems to be more concerned with contributing only to positive aspects regarding the use of ICT for tuition and research. ICT is essential and plays a meaningful role in changing and modernising educational systems as well as the way of learning (Noor-Ul-Amin, 2013; Froumin \& Remorenko, 2020; Fuchs, 2021). This is an indication of the trend or evolution of education which is rising into one positive direction in spite of hindrances. Currently, ICT is known to contribute to the adoption of OER in higher education institutions, including those that are primarily open distance e-learning (ODeL) in nature (Nayak, Kant \& Anjali, 2020).

Both social inclusion and exclusion must be established factors in the higher education domain, particularly in terms of the appropriation of OER. Therefore, the present study sought to identify the causality contributing to both the social inclusion and the social exclusion caused by the use of ICT. The fundamentals of this study are significance to identify the ICT opportunities and gaps encountered in adoption of OER for tuition and research. This might benefit both academics and institutions in clarifying their current position regarding the appropriation of ICT. It is believed that if both social inclusion and exclusion are determined, it can easily assist in the implementation of long-term goals to advance of OER in academia. In addressing the current problem, the paper is structured as follows: a brief description of the study context; a literature review, based on the objective of the paper; use of the model of technology appropriation (MTA) as the study's main theoretical underpinning; the appropriately opted for methodology; the main findings; the discussion of the findings; and the conclusion of the study.

\section{Contextual Settings: Open Distance E-Learning}

The present study was conducted in the South African higher education setting, consisting of 26 universities, which are commonly referred to as higher education institutions. The universities are classified into four categories, namely: traditional universities; comprehensive universities; universities of technology; and ODeL universities (South Africa. Department of Higher Education and Training, 2019). The researchers chose ODeL as their main research context, as the universities concerned rely on ICT and OER to support their tuition and research in the e-learning environment (Van Heerden \& Goosen, 2020). Once students are registered with the ODeL universities, they receive their study material online and or by post. Teaching and learning occur virtually, with it being supported by the appropriate learning management systems (LMSs) (e.g. myUnisa) (Mncube, 2020). In particular, the study was conducted at the University of South Africa (Unisa), which is a South African higher education institution that is classified as falling under the ODeL umbrella.

\section{Literature Review}

The literature seems to have not fully conceptualised the terms social inclusion and exclusion. Social inclusion is mostly defined in relation to social exclusion (Rawal, 2008). Inclusion refers to an individual or group of people who are involved in particular social activity in an organisation (Atkinson, 1998). Social inclusion may refer to a process encouraging social interaction between people with different socially relevant attributes or a careful societal mechanism of opening up access to participation in all spheres of social life (Silver, 2015). Social exclusion is the opposite and as defined as the process through which individuals or group are partially excluded from full participation in the society in which they belong (Fransis, 1997). In this study the terms social inclusion and exclusion are particularised in the appropriation of ICT when adopting or developing OER. The study is influenced by Van Winden (2001) who postulated that ICT can both support social inclusion lead to social exclusion. Therefore, the related literature is reviewed based on the following themes: ICT infrastructure; adoption of OER; and ICT causality on inclusion and exclusion in higher education institution.

\subsection{The Education Sector and Infrastructure in South Africa}

In developing countries, and especially in South Africa, the current communities are structured differently in the urban and rural areas. Whereas the urban areas have seen improvements concerning the ICT infrastructure, connectivity and service delivery (Lembani, Gunter, Breines \& Dalu, 2020; Maciejewski, Currie \& O'Farrell, 2021), the rural settings still lack appropriate infrastructures, including the road networks that are necessary for adequate service provision, as well as the required electricity networks, connectivity and ICT provision (Matli \& Ngoepe, 2020).

In South Africa, learners are expected to enrol for their basic education, which lasts from Grade R to Grade 12 (South Africa. Department of Basic Education, 2010). Once the learners from the urban and rural communities have completed their basic education schooling (i.e., Grade 12), they must decide whether or not to enrol for tertiary 
education. Such education is provided by both private and public universities, all offering bachelor's, master's and doctoral degrees (OECD, 2020). The qualifications obtained after completing tertiary education enable those concerned to search independently for work and/or to open their own business. Some rurally based graduates then opt to pursue further studies remotely (Mubangizi, 2021), while others relocate to the cities to register at more traditional universities (Walker \& Mathebula, 2020).

Most South African universities are city-based. Some students succeed despite the challenges that are posed them, as the culture of education is instilled in South African society. Such a situation is evidenced by the literature, which postulates that, between 2001 and 2011, continuous growth has occurred in the form of student enrolment in schools (South Africa. Statistics South Africa, 2021). The relevant literature affirms that the South African higher education institutions tend to be well structured, with good ICT infrastructure in place, supplied with reliable connectivity (Mashile, Fynn \& Matoane, 2020; Maphalala \& Adigun, 2021). For example, a study that was conducted at the University of Cape Town, which is an urban university, opines that, due to the impoverished background of some (black) students who attend such higher education institutions, their performance tends to be inferior to that of their white counterparts, as a result of the inequalities that still exist in South Africa (Lee Shong, 2020). Therefore, those students who have succeeded to attain tertiary education level face new realities of having to interact with ICT, with some of them never before having used a computer, and not having been exposed to information technology. Their lack of exposure tends to perpetuate the issue of ICT social inclusivity/exclusivity.

\subsection{The Use of OER in Developing Countries}

Globally, the term OER is becoming popular in higher education institutions. The phenomenon has created debates in research, as some scholars opine that the adoption and utilisation of OER has not advanced in the developing countries as it has done in the developed countries (Karakaya \& Karakaya, 2020). Contrary to the above, in both the developed and the developing countries, a rapid increase in the development and use of OER in higher education institutions has occured (Mtebe \& Raisamo, 2014).

The nature of OER provides both academics and students with free access to openly licensed educational materials, so that they can utilise, manipulate and distribute knowledge for their own purposes, in both formal and informal education (Unesco, 2002). The existence of OER is based on the granting of permission that is initiated to retain, reuse, revise, remix and redistribute the resources concerned (Tang, Lin \& Qian, 2020). OER are promoted as a panacea by means of which to overcome educational inequity (Cobo, 2013; Bozkurt, Koseoglu \& Singh, 2019), based on their nature as being developed, adopted and disseminated through ICT. Hence, coming to understand the existing gaps that are present in the accessing of OER, the use of OER, and the impact of OER in the Global South higher education contexts, can be seen to be of significant worth (Cox \& Trotter, 2016; King, Pegrum \& Forsey, 2018).

As a result of the above, the utilisation of OER in the Global South is under investigation. Although use of the term is popular, it still does not mean that the utilisation of such resources is taking place or growing. In fact, the levels of OER creation, use and adoption among learners, practitioners and educational circles have remained disappointingly low (Karakaya \& Karakaya, 2020). Some of the significant factors impeding more active engagement lie in the issue of the language of instruction employed in OER (Hatakka, 2009; Hodgkinson-Williams \& Trotter, 2018), whereas others relate to the existence of multiple barriers, including the prevailing dearth of knowledge, awareness, skills, positive attitudes and internet connectivity (Mtebe \& Raisamo, 2014; Shams, Haq \& Waqar, 2020; Tlili, Ofosu \& Zhang, 2021). Such a situation has placed the higher education institutions in developing countries in the position of having to provide system-based solutions that are aimed at creating a viable environment for the creation and utilisation of OER.

\subsection{ICT and Social Inclusion in the Education Sector}

OER cannot be treated separately from ICT, because they embrace the provision of tuition and research in many different spheres of education. ICT can be seen as a relevant tool for promoting social inclusion, because some educational resources, like OER, are created and utilised through ICT (Tlili, Zhang, Papamitsiou, Manske, Huang \& Hoppe, 2021). Social inclusion consists of the full participation of everyone in a society (Collins, 2003), through the meaningful elimination of any barriers involved (Marston \& Dee, 2015). Such inclusion requires that all the individuals in a particular domain (e.g. in higher education institutions) have equal access to the same opportunities (Martin \& Cobigo, 2011). ICT is the main driver for social inclusion in many spheres of life (Eguavoen, 2016), including gender equality, the economy, politics and education (HDRO, 2015).

Accordingly, ICT has the potential to promote social inclusion within the education sector (Amtallah, 2020). For example, ICT enables academics, worldwide, to share their resources, in the form of OER, and the use of OER also promotes the reduction of educational costs (Ochieng \& Gyasi, 2021). The adoption of ICTs by educational institutions 
is essential for supporting student learning (Chen \& Wu, 2020). Moreover, ICT helps academics and students make informed decisions and adopt responsible measures to ensure the integrity and viability of the educational environment. Such assistance further fosters the supply of quality, comprehensive and transformative education, which, inevitably, serves to affect learning outcomes positively (Bonini, 2020). Lastly, ICT supports social inclusion, by means of enabling sustainable education through the provision of e-tutorials, smart campuses, massive open online courses (MOOCs), blended learning environments (BLEs), technology-enhanced learning (TEL), digital badges and virtual learning environments (VLEs) (González-Zamar, Abad-Segura, López-Meneses \& Gómez-Galán, 2020).

\subsection{ICT and Social Exclusion in the Education Sector}

Besides all the aforementioned OER opportunities and advantages, the way in which OER are adopted, created and distributed can worsen social exclusion. Social exclusion exists due to "the lack or denial of resources, rights, goods and services, and the inability to participate in the normal relationships and activities, available to the majority of people in society, whether in economic, social, cultural, or political arenas" (Levitas et al., 2007: 9). Limited access to ICT can contribute to social exclusion in many domains.

In the context of higher education, even if universities were to improve their online systems of teaching, learning and research (Makgahlela, Mothiba, Mokwena \& Mphekgwana, 2021), in many instances doing so would still not suffice for some students who lack access to an efficient ICT infrastructure at home (Anifowoshe, Aborode, Ayodele, Iretiayo $\&$ David, 2020). The fact remains that many of the students who are flocking to higher education institutions in South Africa, still lack the necessary ICT skills and access due to them coming from the rural areas and townships. They face barriers relating to the high cost of internet connection and because of their lack of knowledge of how to appropriate the digital platforms concerned (Matli \& Ngoepe, 2020). Although many institutions are proposing to supply most registered students with devices for e-learning, them doing so still does not end the social exclusion involved, because most of the communities in the rural areas and in townships still lack network coverage (Dube, 2020).

In South Africa, many students enrol for tertiary education through distance e-learning institutions, while they themselves still reside in the rural areas of the country (Maheshwari, Gupta \& Goyal, 2021; Songca, Ndebele \& Mbodila, 2021). However, studying within an e-learning context requires a proper ICT infrastructure (Pham, Dao, Nguyen-Thanh, Cho \& Pham, 2021) and the lack of electricity and internet connectivity remain a challenge for most such students. The above implies that poverty and the lack of ICT resources and infrastructure tend to inhibit the students' ability to exploit the education systems involved (Alderete, 2017).

\section{The Theoretical Underpinning: Model of Technology Appropriation}

The study interest was to establish factors contributing to social inclusion and exclusion in the appropriation of OER. The study opted to use the MTA (Carroll et al., 2002) to investigate the research question. The MTA, which unpacks the process through which a technological artefact is adopted and transformed (Carroll et al., 2002), consists of three major variables, namely technology-as-designed, the process of appropriation and technology-in-use. Firstly, the technology-as-designed variable refers to technological artefacts that are designed for, and then supplied to, a target audience, with the artefacts involved containing implicit models of their intended users (Law \& Bijker, 1992). The variable concerned helped by determining the types of technology and system owned by the ODeL institution studied. The existing systems are recognised as influencing users, in terms of the causality of non-appropriation and the actual appropriation process of the OER.

Secondly, the appropriation process involves the users trialing and evaluating the technology, selecting and adapting some of its attributes, and, so, taking possession of its capabilities, so as to satisfy their needs (Carroll et al., 2002). Doing so encourages developing an understanding of the way in which different groups of users select or modify aspects of technology, shape it to their needs and, thus, take possession of the variable concerned to help to establish what ICT artefacts are used by academics to appropriate OER. The phase involved also allows for the non-appropriation, the appropriation, and the dis-appropriation concerned to contribute to the social inclusion and exclusion involved. The phase also shows who the enforcers of OER are and what they do, so that they can be well appropriated within the ODeL context. Lastly, the technology-in-use variable describes the way in which user groups use technology, with their embedding, or incorporating, of technology implying some sense of stabilisation of technology, with the use of new technology having become natural (Monteiro, 1998). In terms of the variable concerned, the study could establish the type of systems and technologies used by academics during the appropriation of OER. Overall, the application of MTA variables was able to identify the influences of each variable involved by means of considering how they contribute either to social inclusion or to social exclusion. Therefore, the MTA was tested and seemed to be relevant to establish factors related to social inclusion and social exclusion during the appropriation of OER in a higher education context. 


\section{The Research Methodology}

The study focused on a single heterogeneous case study at an ODeL university. The study followed the qualitative approach through the lens of interpretivism. The participants were selected in line with the fact that they utilised ICT for purposes of tuition and research, within the ODeL context. The study primarily targeted academics, because such professionals are responsible for the adoption and development of OER. Academics can also recognise the potential for exclusion that is caused by ICT.

In addition to academics, OER champions were also targeted, because they are the ones encouraging or enforcing academics to take the initiative in the adoption, development and dissemination of OER for reasons of tuition and research. Also, OER champions tend to be in a relatively good position to be able to direct academics to the relevant ICT infrastructure for use during the appropriation process. A librarian also formed part of the sample, as the library plays a role in an academic institution, in the form of distributing and disseminating OER. Therefore, all the participants contributed to determining the impact of ICT as a role-player in terms of social inclusion and social exclusion during the appropriation of OER. In total, 48 semi-structured interviews were conducted, with two focus groups being conducted as part of the study. Based on the participants' representation, the sample size was considered to be sufficient to investigate the domestication process. Moreover, based on the researchers involvement in transcriptions, analysis, and presentation of data, it was easy to recognise the saturation point. Data saturation is reached when there is enough information to replicate the study and when additional new information can no longer be obtained, and when further coding is no longer feasible (Fusch \& Ness, 2015). Table 1 highlights the participants' demographics.

Table 1. The demographic characteristics of the participants

\begin{tabular}{|c|c|c|c|c|c|}
\hline Participants & Female & Male & $\begin{array}{l}\text { College/library } \\
\text { representation }\end{array}$ & $\begin{array}{l}\text { Semi-structured } \\
\text { interviews }\end{array}$ & $\begin{array}{l}\text { Focus groups } \\
\text { (FGs) }\end{array}$ \\
\hline $\begin{array}{l}\text { Academic staff: } \\
\text { - } \quad \text { junior lecturers } \\
\text { - } \\
\text { - lecturers } \\
\text { - } \\
\text { - } \\
\text { - } \\
\text { assonior lecturers } \\
\text { professors }\end{array}$ & 24 & 18 & 8 colleges & 42 & 2 \\
\hline OER champions & 3 & 2 & 5 colleges & 5 & 0 \\
\hline Librarian & 1 & 0 & Library & 1 & 0 \\
\hline Summary of participants & 28 & 20 & 9 & 48 & 2 \\
\hline Total number of participants & 50 & & & & \\
\hline
\end{tabular}

The data involved were collected from 2019 to 2020, using semi-structured interviews. The research instrument was developed based on the MTA variables. The data collection was done during face-to-face interviews and online interviews, using virtual platforms like MS Teams. The interviews typically took place in the academics' own offices on the different campuses of the ODeL institution. Each interview lasted between 30 and 60 minutes. To allow for triangulation, document analysis was also conducted. The specific documents that were reviewed and analysed including the institution's OER strategy, the Open Distance Learning Policy and Unisa's annual reports (from 2013 and 2019). The researchers also consulted the OER library portals within the institution's own repository, so as to learn how OER are developed. During the data collection, the data were recorded, with them later being transcribed into text format. The transcribed data were coded into NVivo for data analysis. The study opted for thematic analysis.

\subsection{Ethical Considerations}

The current researchers obtained permission from the ODeL university concerned to conduct the study at their institution. The institution of higher learning indicated in the ethical clearance letter and in its letter of permission that its identity could be revealed. Permission to conduct the interviews held was obtained on condition that all the ethical procedures were adhered to, including anonymity, the right to participate, and the right to withdraw at any time from the research if the university so desired. 


\section{Findings}

As has already been mentioned, the aim of the study was to establish how ICT influences social inclusion and exclusion, during the appropriation of OER. To contextualise the findings, an overview of the ICT landscape at the ODeL institution is first provided below. Insights into how ICT contributes to social inclusion and exclusion during OER appropriation are also provided. Figure 2 shows how adopting the MTA contributed to the data presentation and findings.

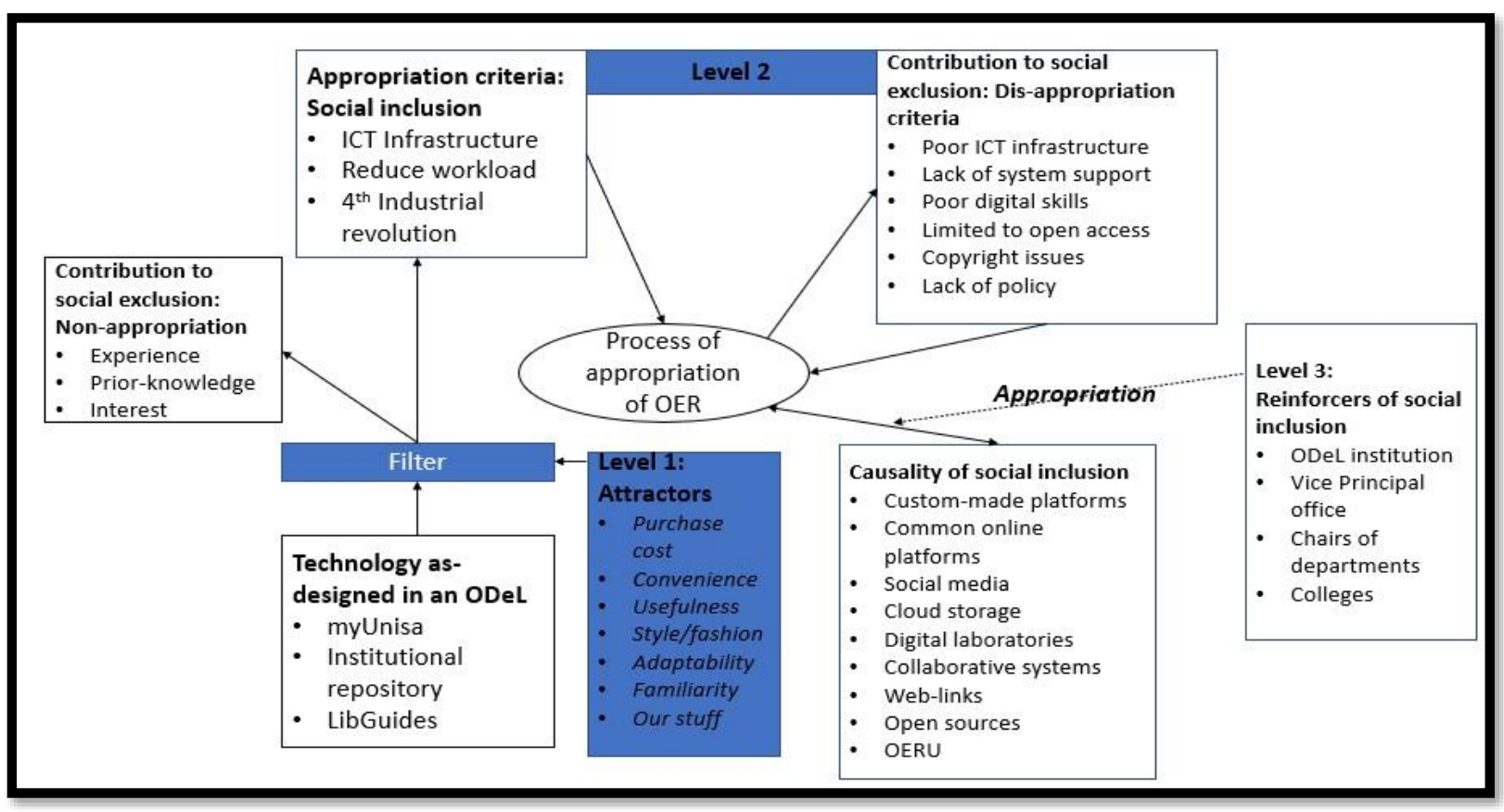

Figure 1. ICT factors leading to social inclusion and exclusion in the appropriation of OER

\subsection{ICT Landscape at the ODeL Institution}

Most of the participants mentioned that they relied on the ODeL institution's LMS for storing and disseminating their OER. Some explained that they relied on the LMS due to it being the official platform used by the ODeL institution. The LMS also integrated easily with the library system, making it easy for them to manage their own OER. The participants specifically used the LMS for the management of their courses, for storing content, for marking assignments, for obtaining instant interaction with the students, and for catering for their research needs. Some of the participants revealed that they preferred to use the LMS due to its simple user interface, which allowed for easy engagement and interaction. They also commended the platform for its adaptability, as it enabled them to interact with the students and to embed various media modalities that were relevant to teaching and learning.

In addition to the LMS, the participants explained that they relied on the institutional repository to store their OER and research outputs. The institutional repository is an online academic library system that is used for the data management, the preservation and the dissemination of the intellectual output of institutional research (Lynch, 2003). Table 2 summarises the participants' responses regarding the systems and the information technology used by the faculty and academic staff at the ODeL institution concerned, for purposes of tuition and research. 
Table 2. Examples of quotes from the ICT landscape overview

\begin{tabular}{ll}
\hline Emerged themes & Related participants responses \\
\hline Learning management system & "I usually post those OER in the institutional (i.e. LMS) system and again, after \\
that, I ve got to market those OER to students, so that they can be able to utilise & them" (Junior Lecturer 1). \\
"No, I think myUnisa is key to any academic right and our students have been \\
aligned to myUnisa so directly, so there are no other systems that I'm using \\
besides myUnisa" (Senior Lecturer 6). \\
"You have got to create this thing, take it to the Library and then wait for them to \\
put it in the institutional repositories" (Lecturer 8). \\
"I will probably put it on the OER ... Unisa has now got an OER repository \\
through the Library, so I will put it up there" (Lecturer 16).
\end{tabular}

6.2 Social Inclusion

The majority of the participants indicated many different ICT aspects that contribute to social inclusion. Based on the findings obtained, the researcher involved realised that most of the positive responses related to, or were based on, the support of social inclusion. Besides many positive responses regarding the ICT employed, the study formulated two major themes that were significant for the findings and data discussion. Such themes were the causalities of ICT affordability in the appropriation of OER, and the provision of OER support for e-learning. Table 3 below illustrates the participants' responses related to ICT affordability and to the ICT for securing online realities.

Table 3. Participants' responses related to social inclusion

\begin{tabular}{|c|c|}
\hline Emerged themes & Related responses of participants \\
\hline $\begin{array}{l}\text { Causality of ICT } \\
\text { affordability in the } \\
\text { appropriation of }\end{array}$ & $\begin{array}{l}\text { "In my institution, there is good internet coverage and the ICT infrastructure, I like it, because } \\
\text { it can enhance my tuition. I can easily access and create resources for my students" (Lecturer } \\
8) \text {. }\end{array}$ \\
\hline OER & $\begin{array}{l}\text { "If the ICT infrastructure is user-friendly, it's good. It becomes very easy for all the students, } \\
\text { educators and people in general to access information from these OER" (FG1_Lecturer 2). }\end{array}$ \\
\hline $\begin{array}{l}\text { OER support for } \\
\text { e-learning }\end{array}$ & $\begin{array}{l}\text { "A large majority of our students are also millennials, and they prefer instant interactive } \\
\text { learning ... you might need to use more visual content in a form of online learning" (Lecturer } \\
\text { 22). }\end{array}$ \\
\hline & $\begin{array}{l}\text { "So, we make use of this open resource to teach students, but this open-source resource also } \\
\text { comes with content like ... SQL manuals, so the students will make use of these OER which } \\
\text { were designed to be used within ... which makes everything free open source and open } \\
\text { content" (Senior lecturer 5). }\end{array}$ \\
\hline
\end{tabular}

Enforcers of OER "In this department, I was questioned about OER in IPMS [performance bonus]. The COD adoption and [Chair of Department] asked if I have got any evidence of using OER in my teaching and development learning" (Lecturer 4).

The participants stated that they considered ICT to be an enabler of the appropriation of OER. The study findings show that the institutional ICT systems have a role to play in social inclusion, during the appropriation of OER. They further mentioned that ICT affords the faculty, the students and the other employees the ability to perform their daily duties conveniently. Also, the institution has a leading role to play in encouraging academics to adopt and develop OER. In such a situation, ICT serves as an enabler of OER. The participants mentioned that OER are ICT-driven resources, since they are created, used and accessed through online platforms (e.g. LMS and the institutional repository). Moreover, the participants confirmed that they were appropriating OER, because they had an appropriate ICT infrastructure. Some mentioned that the ODeL university relies heavily on the ICT infrastructure when adopting and developing OER. Besides the above, activities such as management, administration, tuition and research take place through ICT. Hence, given that the institution studied tends to have relatively little physical interaction with its students, it has come to rely on an online mode of teaching, learning, research and administration, which can only be supported through the ICT infrastructure by way of using OER for tuition and research. 
Some participants mentioned that the use of OER enhances e-learning. They also stressed the importance of innovating when appropriating OER, by means of using custom-made virtual platforms, open-source platforms, Open Educational Resource (OER) Universitas, shadow ITs, and many other technologies. Apart from tuition and research, the findings showed that having ICT capabilities could afford the Library a chance to create, distribute, manage and disseminate OER. Accordingly, using OER could offer additional opportunities for students, academics and any outsiders who are seeking information from inside the institution to access OER. As some of the participants in the study mentioned, they are also able to be innovative in their practice, in terms of using ICT to manipulate some of the open-source content, so as to create additional online courses that are accessible to all for free. Such ability to manipulate content is an indication that both ICT and OER can be used to create an enhanced space for education and work. Furthermore, some academics mentioned that using OER affords opportunities to make education more interesting and attractive to contemporary students, given that such students tend to be interested in interactive and virtual learning spaces.

\subsection{Social Exclusion}

The study found several challenges relative to ICT use that inhibited the successful appropriation of OER, which further contributed to social exclusion. In particular, the participants encountered numerous ICT-related challenges that lead either to the non-appropriation or to the dis-appropriation of OER. As a result, the potential of OER for teaching, learning and research was not realised, hence leading to social exclusion. Table 4 represents the emerging themes and the participants' responses, associated with social exclusion.

Table 4. Participants' responses related to social exclusion

\begin{tabular}{|c|c|}
\hline Emerged themes & Related responses of participants \\
\hline \multirow[t]{2}{*}{ Non-appropriation of OER } & $\begin{array}{l}\text { "No [I do not have prior knowledge], I experienced the OER in 2018, luckily, when I } \\
\text { arrived here in an ODeL institution" (Junior Lecturer 2). }\end{array}$ \\
\hline & $\begin{array}{l}\text { "I didn't have an opinion, because I came from the corporate world to Unisa" (Lecturer } \\
\text { 17). }\end{array}$ \\
\hline \multirow[t]{3}{*}{$\begin{array}{l}\text { Dis-appropriation of OER } \\
\text { due to ICT challenges }\end{array}$} & $\begin{array}{l}\text { "Using ICT means you must have money for data and all of that [so as to be able] to } \\
\text { access the internet to access the OER" [FG1_Lecturer 1]. }\end{array}$ \\
\hline & $\begin{array}{l}\text { "Hindrances are poor ICT infrastructures. When there is poor ICT infrastructure, it } \\
\text { becomes very difficult to access the OER" [Lecturer 9]. }\end{array}$ \\
\hline & $\begin{array}{l}\text { "We teach people for the } 21 \text { st century's ... students chose to enroll in an ODeL, and they } \\
\text { are aware that the requirement is ICT. Also, we are training them to be compatible in the } \\
\text { digital world" [OER Champion 5]. }\end{array}$ \\
\hline
\end{tabular}

The initial study inquiry concerned the technology designed in an ODeL institution, with such an inquiry being made to establish the causality of non-appropriation. In terms of the above, if the artefact is not appropriated, it can be considered to contribute to social exclusion. Some academics opined that they could not appropriate OER, because they were unfamiliar with the phenomenon, as the occasion of the study was the first time that some heard about the resource. The issue of knowledge was another contributing factor to non-appropriation, with some participants opining that they lacked OER-related knowledge, including skills of adoption and development. Other participants fell into the non-appropriation category, due to them not being interested in utilising OER for their tuition and research.

Some of the participants opined that ICT contributes to the dis-appropriation of OER. Most of the participants were found not to be impacted by the many different ICT-related challenges (e.g. poor infrastructure) existing at the ODeL institution. In the light of such challenges, the participants explained that their students were the main stakeholders to be impacted on continuously by the lack of ICT infrastructure. The participants felt that, even if they developed OER for teaching and learning, and recommended them to their students, that it was not guaranteed that the latter would utilise the OER resources, due to their lack of funds to purchase data bundles to connect to the internet. The finding made in the above regard might, consequently, indicate that accessing OER is not free, as the relevant literature postulates. Hence, the existence of such a persistent problem might contribute to the social exclusion of students in their quest for enhanced education. In short, any student who faces ICT-related constraints is unable to appropriate OER for tuition and research, as having such access to OER presupposes the existence of a reliable ICT infrastructure by means of which the resources concerned can be accessed.

Although a reliable ICT infrastructure was in place at the ODeL institution studied, some participants explained that certain barriers to accessing OER still existed. In particular, the current ICT infrastructure (and, therefore, the OER) is only accessible to the ODeL institution's staff and students. External users cannot access the ODeL OER, despite the 
institution being considered to be an open university. Certain of the participants mentioned that the user had to be a registered student or an employee of an ODeL institution to be able to access an OER. As a result, the participants felt that potential external users were being socially excluded, as, in their opinion, OER resources, like teaching and learning content and research resources, should be accessible to all others. To them, being excluded from being able to access such resources led to social exclusion, because being unable to do so hindered any other potential users from accessing the OER created or developed by the ODeL institution concerned.

\section{Discussion}

In appropriating OER in the ODeL context, ICT contributes to both social inclusion and exclusion. In terms of the social inclusion perspective, the study findings show that most of the participants agreed that the current ICT infrastructure enabled the appropriation of OER. Also, OER have been proved to promote e-learning. Such findings affirm that an ODeL institution, as well as any other South African university, does well in establishing an ICT infrastructure for its employees and academics, for purposes of educational processing (Anifowoshe et al., 2020; Makgahlela et al., 2021). The above might indicate that South African universities tend to be the forerunners in terms of providing facilities and infrastructures on the African continent (Dodoo, Al-Samarraie \& Alzahrani, 2021; Phale, Fanglin, Adjei Mensah, Omari-Sasu \& Musah, 2021).

An ODeL institution can promote social capitalism, which can, in turn, contribute to social inclusion. The study findings also show that the academics surveyed were not in a sufficiently strong position to demand that other academics had the right to appropriate OER. Instead, those who were better suited to do so were the vice-principal's office, the OER champions, the CODs, the school directors and the deans. The authorities concerned intended to promote social inclusion, because they had many different initiatives in place, including the training of academics regarding OER, as well as the provision of incentives and bonuses, and of all necessary resources for adoption and development. The above implies that social capital plays a key role in the higher education advocacy of OER.

Therefore, the findings and the literature covered in the current study confirm that, in the ODeL institution surveyed, the ICT provision had not yet reached the stage to provide social inclusivity to its full extent. Social inclusion can only be fully realised if all the individuals within the society or the institutions concerned are afforded equal opportunities and rights (Collins, 2003; Martin \& Cobigo, 2011). The critical need to provide services to both employees and students at the higher education level is evident. In the event that both the employees' and the students' needs are not equally met, opposition exists to social inclusion. The situation, as found, afforded the current researchers the opportunity to suggest the following proposition:

Proposition 1: The ICT innovations for OER adoption and development cause the advancement of e-learning in those spaces where positive social capitalism is practised.

Social exclusion exists in the ODeL institution, due to the persisting challenges that are related to social needs and resources. The inability to appropriate OER contributes to the phenomenon of social exclusion. The current study's findings show that the lack of knowledge, interest and experiences is the main cause of the non-appropriation of OER. The findings concerned are in line with Carroll et al.'s (2001) postulation that choosing not to discover the capabilities of ICT, or failing to explore and evaluate the artefacts involved, result in the non-appropriation of OER. Mncube, Tanner and Chigona (2021) confirmed that, if users lack prior knowledge and interest, and if they exhibit a negative attitude regarding OER, the appropriation phase cannot be initiated, but, instead, the non-appropriation phase will prevail. As is evident in the literature and empirical findings discussed, the present study interprets non-appropriation as being a social exclusion action.

Where the participants stated that they were able to start appropriating OER, some experienced uncertainty regarding the students' infrastructure, the lack of student support, certain copyright issues and the lack of policy. Dis-appropriation occurs where users decide to stop using the technology involved, which may occur either early or late in the process of appropriation (Carroll et al., 2002). The participants concerned further opined that dis-appropriation can be described as resulting from the development of challenges to usage cost, health, reception, the usability of artefacts and the ease of learning. Coherence exists between the relevant literature and the findings made, with the study alluding to the hindrances leading to dis-appropriation. The factors involved were found to contribute to the dis-appropriation of OER, with all the dis-appropriation factors being found, in turn, to relate to the financial resources available. In short, the appropriation of OER is not free in the developing countries. The findings of the current study show that the adoption, development and utilisation of OER cannot be described as being freely available in South Africa, or in any other developing country, as the issue of ICT infrastructure and internet connectivity and access remains a challenge (Mncube, 2020; Makgahlela et al., 2021). Only once the issues of inequality and of ICT 
social exclusion are addressed and resolved might it become possible to affirm that OER are a free resource within the developing context. The above gives rise to the opportunity to suggest the following proposition:

Proposition 2: The non-appropriation and the dis-appropriation of the educational artefact are the main influences contributing to social exclusion in the academic institution.

\section{Conclusion}

In inquiring about whether the contributions that are made by ICT tend to promote either social inclusion or social exclusion during the appropriation of OER in an ODeL context, the current study found that ICT is the main enabler in terms of the appropriation of OER. However, the ODeL academics confirmed that ICT and OER are contributing factors to social inclusion, and they expressed their appreciation of the fact that their well-being is reliant, at least to some extent, on ICT provision. Nevertheless, some academics are still concerned about the well-being of their students, as they assume that students are not fully provided with appropriate ICT and OER infrastructures to support their learning. The academics' perception might be relevant, as most studies conducted in South African higher education institutions allude to students being poor (Mpungose, 2021) and lacking relevant infrastructure (Mashile et al., 2020; Matli \& Ngoepe, 2020; Maphalala \& Adigun, 2021). Past studies also found that students tend to struggle with poor network connectivity (Dube, 2020; Mncube, 2020) and inadequate access to electricity (Murshed, 2020). In the light of the above, the appropriation of OER might be difficult, despite the need to adopt and develop them. OER, which have proved to be promoters of e-learning, can be successfully developed, and distributed where an ICT infrastructure exists. In general, OER exist on a digital platform that is sharable among users (UNESCO, 2002).

The researchers found that the tertiary education institution surveyed tends to adopt and develop OER for students, although the affordability of ICT was noted as being the main factor of dis-appropriation for those who had started utilising OER. The study recommended that the ODeL institution should revisit its intellectual property policy to benefit students and other scholars. The majority of Unisa resources, including study guides and course outlines, should be accessible globally. ODeL institutions have the possibility of, and the responsibility for, playing a leading role in promoting the fair and equal distribution of African knowledge on the continent. To fulfil such a role, they should consider making more of their OER content accessible to a wider audience across the continent. ODeL institutions should also be more cognisant of the limited access to ICT infrastructure that some students have. Only then can social inclusion be realised to its fullest extent. In realising such limitations, policies could be adapted to support the needs of the students more effectively than they are at present.

To fast track the appropriation of OER, in terms of the issue of ICT infrastructure and network coverage, Unisa and the South African government should collaborate with such internet service providers as Telkom, Vodacom, MTN, CellC and others to ensure that at least all South African locations have access to fibre optics to facilitate network coverage. Once such a network has been rolled out, it could be extended to the population-intense rural areas, keeping in mind that more Unisa students are to be found in highly populated areas. Such extension of ICT services must occur as a matter of priority because the statistics show that Unisa's student enrollment is a third of the South African student population, with the majority being poor students who reside in the township and rural areas. Achieving such outreach might result in the eliminating of persistent complaints about ICT infrastructure and network connectivity. South African communities, including those with students, have gradually increased their ownership of devices to a range of 67 per cent (Aheto \& Cronje, 2018). In terms of such an occurrence, devices are becoming irrelevant and losing value, due to the lack of network coverage and the relative inaccessibility of internet connections for keeping the systems up to date (in regard to operating system updates).

Additionally, the ODeL sector should revisit its policies and procedures, so as to ensure adherence to openness in terms of open university capacity regarding access to content, as well as in terms of granting access to ICT resources, including hardware and software. Some academics have even gone so far as coming to rely on shadow IT for distributing and administering OER. Unisa, as an open university, should be proud to share its teaching resources with any other South African institution. If Unisa's academics were to rely on shadow IT, the impact would be felt by other institutions that have made their resources and systems free for the purpose of knowledge distribution. Unisa, as the topmost open institution in Africa, including South Africa, must drive the mandate of making knowledge openly accessible to all through enabling access to its tuition and research resources. In seeking to establish the role of ICT as a contributing agency to social inclusion and exclusion at an ODeL university, the necessary literature and empirical findings provided evidence of such. In short, the current study has realised the opportunity and the need to investigate the nature of ODeL students, relative to the current status of ICT and wireless network coverage as a major contributor to social exclusion. 


\section{Acknowledgment}

This research is part of unpublished PhD study which was registered at the University of Cape Town with the title "The domestication of open educational resources by academics in an open distance e-learning university of South Africa". This project is funded by the National Institute for the Humanities and Social Sciences (NIHSS) and collaborates annually with the South African Humanities Deans Association (SAHUDA).

\section{References}

Alderete, M. V. (2017). Examining the ICT access effect on socioeconomic development: The moderating role of ICT use and skills. Information Technology for Development, 23(1), 42-58. https://doi.org/10.1080/02681102.2016.1238807

Al-Rahmi, W. M., Alzahrani, A. I., Yahaya, N., Alalwan, N., \& Kamin, Y. B. (2020). Digital communication: Information and communication technology (ICT) usage for education sustainability. Sustainability, 12(12), 5052. https://doi.org/10.3390/su12125052

Amtallah, A. K. (2020). Institutional factors influencing students' preparedness on integration of information and communication technology in teaching and learning: Case of Eregi Teachers Training College, Kenya [Unpublished doctoral dissertation]. University of Nairobi.

Anifowoshe, O., Aborode, A. T., Ayodele, T. I., Iretiayo, R. A., \& David, O.O. (2020). Impact of COVID-19 on education in sub-Saharan Africa. Preprints. https://doi.org/10.20944/preprints202007.0027.v1

Atkinson. A. B. (1998). "Social Exclusion, Poverty and Unemployment" in A. B. Atkinson and J. Hills Exclusion, Employment and Opportunity, CASE Paper 4, London: Centre for Analysis of Social Exclusion, London School of Economics

Bala, M. (2018). Use of ICT in higher education. Multidisciplinary Higher Education, Research, Dynamics \& Concepts: Opportunities \& Challenges for Sustainable Development, 1(1), 368-376.

Bates, A. W. (2015). Teaching in a digital age: Guidelines for designing teaching and learning. Bates.

Bonini, P. (2020). When tomorrow comes: Technology and the future of sustainability learning in higher education. Environment: Science and Policy for Sustainable Development, 62, 39-48. https://doi.org/10.1080/00139157.2020.1764300

Bozkurt, A., Koseoglu, S., \& Singh, L. (2019). An analysis of peer reviewed publications on openness in education in half a century: Trends and patterns in the open hemisphere. Australasian Journal of Educational Technology, 35(4). https://doi.org/10.14742/ajet.4252

Brown, A., \& Green, T. (2009). Issues and trends in instructional technology: Web 2.0, second life, and STEM share the spotlight, In Educational media and technology yearbook (pp. 7-23). Springer. https://doi.org/10.1007/978-0-387-09675-9_2

Carroll, J., Howard, S., Peck, J., \& Murphy, J. (2002). A field study of perceptions and use of mobile telephones by 16 to 22 year olds. Journal of Information Technology Theory and Application, 4(2), 49-61. http://aisel.aisnet.org/cgi/viewcontent.cgi?article=1178\&context=jitta

Carroll, J., Howard, S., Vetere, F., Peck, J., \& Murphy, J. (2001). Identity, power and fragmentation in cyberspace: Technology appropriation by young people. ACIS 2001 Proceedings, 6.

Chen, C. L., \& Wu, C. C. (2020). Students' behavioral intention to use and achievements in ICT-integrated mathematics remedial instruction: Case study of a calculus course. Computers \& Education, 145, 103740. https://doi.org/10.1016/j.compedu.2019.103740

Cobo, C. (2013). Exploration of open educational resources in non-English speaking communities. International Review of Research in Open and Distributed Learning, 14(2), 106-128. https://doi.org/10.19173/irrodl.v14i2.1493

Collins, H. (2003). Discrimination, equality and social inclusion. Modern Law Review, 66(1), 16-43. https://doi.org/10.1111/1468-2230.6601002

Cox, G., \& Trotter, H. (2016). Institutional culture and OER policy: How structure, culture, and agency mediate OER policy potential in South African universities. International Review of Research in Open and Distributed Learning, 17(5). https://doi.org/10.19173/irrodl.v17i5.2523 
Dodoo, J. E., Al-Samarraie, H., \& Alzahrani, A. I. (2021). Telemedicine use in sub-Saharan Africa: Barriers and policy recommendations for Covid-19 and beyond. International Journal of Medical Informatics, 104467. https://doi.org/10.1016/j.ijmedinf.2021.104467

Dube, B. (2020). Rural online learning in the context of COVID 19 in South Africa: Evoking an inclusive education approach. Multidisciplinary Journal of Educational Research, 10(2), 135-157. https://doi.org/10.17583/remie.2020.5607

Eguavoen, E. O. (2016). ICT utilization as correlates of academic performance among students with visual impairment in Lagos State Nigeria. European Scientific Journal ESJ, 12(13), 205. https://doi.org/10.19044/esj.2016.v12n13p205

Francis, P. (1997). "Social Capital, Civil Society and Social Exclusion" in Kothari, Uma and Matin Minouge (eds) "Development Theory and Practice: Critical Perspectives" Hampshire: Palgrave

Froumin, I., \& Remorenko, I. (2020). From the "best-in-the world" soviet school to a modern globally competitive school system. Audacious Education Purposes, 233. https://doi.org/10.1007/978-3-030-41882-3_9

Fuchs, K. (2021). Preparing students for success in a changing world: The role of virtual whiteboards in the modern classroom. Education Quarterly Reviews, 4(1). https://doi.org/10.31014/aior.1993.04.01.182

Fusch, P. I., \& Ness, L. R. (2015). Are we there yet? Data saturation in qualitative research. The qualitative report, 20(9), 1408. https://doi.org/10.46743/2160-3715/2015.2281

González-Zamar, M. D., Abad-Segura, E., López-Meneses, E., \& Gómez-Galán, J. (2020). Managing ICT for sustainable education: Research analysis in the context of higher education. Sustainability, 12(19), 8254. https://doi.org/10.3390/su12198254

Hatakka, M. (2009). Build it and they will come? Inhibiting factors for reuse of open content in developing countries. Electronic Journal on Information Systems in Developing Countries, 37(5), 1-16. https://doi.org/10.1002/j.1681-4835.2009.tb00260.x

Hodgkinson-Williams, C. A., \& Trotter, H. (2018). A social justice framework for understanding open educational resources and practices in the Global South. Journal of Learning for Development, 5(3), 204-224.

Karakaya, K., \& Karakaya, O. (2020). Framing the role of English in OER from a social justice perspective: A critical lens on the (dis)empowerment of non-English speaking communities. Asian Journal of Distance Education, 15(2), 175-190.

Khan, A. (2020). Information communication technology in higher education. Ideal Research Review, 1(21), 50-53.

King, M., Pegrum, M., \& Forsey, M. (2018). MOOCs and OER in the Global South: Problems and potential. International Review of Research in Open and Distributed Learning, 19(5). https://doi.org/10.19173/ irrodl.v19i5.3742

Law, J., \& Bijker, W. E. (1992). Postscript: Technology, stability, and social theory. In W. E. Bijker \& J. Law (Eds.), Shaping technology/building society: Studies in sociotechnical change (pp. 290-308). MIT Press.

Lee Shong, C. (2020). Exploring first-year, rural students' computer acquisition experiences at an urban university in South Africa [Unpublished masters thesis]. University of Cape Town. http://hdl.handle.net/11427/32769

Lembani, R., Gunter, A., Breines, M., \& Dalu, M. T. B. (2020). The same course, different access: The digital divide between urban and rural distance education students in South Africa. Journal of Geography in Higher Education, 44(1), 70-84. https://doi.org/10.1080/03098265.2019.1694876

Levitas, R., Pantazis, C., Fahmy, E., Gordon, D., Lloyd, E., \& Patsios, D. (2007). The multi-dimensional analysis of social exclusion. Department of Sociology and School for Social Policy, Townsend Centre for the International Study of Poverty and Bristol Institute for Public Affairs. https://dera.ioe.ac.uk/6853/1/multidimensional.pdf

Maciejewski, K., Currie, P., \& O'Farrell, P. (2021). Social-ecological connectivity in Global South cities. In C. M. Shackleton, S. S. Cilliers, E. Davoren, \& M. J. du Toit (Eds.), Urban ecology in the Global South (pp. 347-364). Cham. https://doi.org/10.1007/978-3-030-67650-6_14

Maheshwari, M., Gupta, A. K., \& Goyal, S. (2021). Transformation in higher education through e-learning: A shifting paradigm. Pacific Business Review International, 49-63. 
Makgahlela, M., Mothiba, T. M., Mokwena, J. P., \& Mphekgwana, P. (2021). Measures to enhance student learning and well-being during the COVID-19 pandemic: Perspectives of students from a historically disadvantaged university. Education Sciences, 11(5), 212. https://doi.org/10.3390/educsci11050212

Maphalala, M. C., \& Adigun, O. T. (2021). Academics' experience of implementing e-learning in a South African higher education institution. International Journal of Higher Education, 10(1), 1-13. https://doi.org/10.5430/ijhe.v10n1p1

Marston, G., \& Dee, M. (2015). The social inclusion policy agenda in Australia: A case of old wine, new bottles? Australian Journal of Social Issues, 50(2), 119-138. https://doi.org/10.1002/j.1839-4655.2015.tb00340.x

Martin, L., \& Cobigo, V. (2011). Definitions matter in understanding social inclusion. Journal of Policy and Practice in Intellectual Disabilities, 8(4), 276-282. https://doi.org/10.1111/j.1741-1130.2011.00316.X

Mashile, E. O., Fynn, A., \& Matoane, M. (2020). Institutional barriers to learning in the South African open distance learning context. South African Journal of Higher Education, 34(2), 129-145. https://doi.org/10.20853/34-2-3662

Matli, W., \& Ngoepe, M. (2020). Capitalizing on digital literacy skills for capacity development of people who are not in education, employment or training in South Africa. African Journal of Science, Technology, Innovation and Development, 12(2), 129-139. https://doi.org/10.1080/20421338.2019.1624008

Mncube, L. S. (2020). LMS for Information Science students in an open distance e-learning institution in South Africa. In Handbook of research on emerging trends and technologies in library and information science (pp. 266-285). IGI Global. https://doi.org/10.4018/978-1-5225-9825-1.ch018

Mncube, L. S., Tanner, M., \& Chigona, W. (2021). The commodification of open educational resources by academics in an ODeL institution. IFIP Working Group 9.4: Implications of Information and Digital Technologies for Development. https://www.mn.uio.no/ifi/english/research/groups/is/ifip-94/

Mpungose, C. B. (2021). Students' reflections on the use of the Zoom Video conferencing technology for online learning at a South African university. International Journal of African Higher Education, 8(1), 159-178. https://doi.org/10.6017/ijahe.v8i1.13371

Mtebe, J. S., \& Raisamo, R. (2014). Investigating perceived barriers to the use of open educational resources in higher education in Tanzania. International Review of Research in Open and Distributed Learning, 15(2), 43-66. https://doi.org/10.19173/irrodl.v15i2.1803

Mubangizi, B. C. (2021). Rural-urban migration and smart cities: Implications for service delivery in South Africa. African Renaissance, 18(1), 1744-2532. https://doi.org/10.31920/2516-5305/2021/18n1a9

Monteiro, E. (1998). Living with technology. Scandinavian Journal of Information Systems, 10(1\&2), $249-254$.

Murshed, M. (2020). An empirical analysis of the non-linear impacts of ICT-trade openness on renewable energy transition, energy efficiency, clean cooking fuel access and environmental sustainability in South Asia. Environmental Science and Pollution Research, 27(29), 36254-36281. https://doi.org/10.1007/s11356-020-09497-3

Nayak, S. R., Kant, N., \& Anjali, K. (2020). Strategy of using ICT in ODL to disseminate higher education in tribal communities: A case of MP, India. Asian Association of Open Universities Journal. https://doi.org/10.1108/AAOUJ-05-2020-0029

Noor-Ul-Amin, S. (2013). An effective use of ICT for education and learning by drawing on worldwide knowledge, research, and experience. ICT as a Change Agent for Education. India: Department of Education, University of Kashmir, 1-13.

Ochieng, V. O., \& Gyasi, R. M. (2021). Open educational resources and social justice: Potentials and implications for research productivity in higher educational institutions. E-Learning and Digital Media, 18(2), 105-124. https://doi.org/10.1177/2042753021989467

Organisation for Economic Co-operation and Development (OECD). (2020). Education at a glance 2020: OECD indicators. OECD. https://doi.org/10.1787/69096873-en

Phale, K., Fanglin, L., Adjei Mensah, I., Omari-Sasu, A. Y., \& Musah, M. (2021). Knowledge-based economy capacity building for developing countries: A panel analysis in the Southern African Development Community. Sustainability, 13(5), 2890. https://doi.org/10.3390/su13052890

Pham, Q. D., Dao, N. N., Nguyen-Thanh, T., Cho, S., \& Pham, H. C. (2021). Detachable web-based learning framework to overcome immature ICT infrastructure toward smart education. IEEE Access, 9, 34951-34961. https://doi.org/10.1109/ACCESS.2021.3062371 
Rawal, N. (2008). Social inclusion and exclusion: A review. Dhaulagiri Journal of Sociology and Anthropology, 2, 161-180. https://doi.org/10.3126/dsaj.v2i0.1362

Shams, S., Haq, M. A. U., \& Waqar, Y. (2020). Open educational resources (OER) usage trends among university students of Pakistan. Education and Information Technologies, 25, 5637-5654. https://doi.org/10.1007/s10639-020-10195-3

Silver, H. (2015). The contexts of social inclusion. https://doi.org/10.2139/ssrn.2641272

Silverstone, R., \& Hirsch, E. (1992). Consuming technologies: Media and information in domestic spaces. Routledge.

Songca, R. N., Ndebele, C., \& Mbodila, M. (2021). Mitigating the implications of Covid-19 on the Academic Project at Walter Sisulu University in South Africa: A proposed framework for emergency remote teaching and learning. Journal of Student Affairs in Africa, 9(1), 41-60. https://doi.org/10.24085/jsaa.v9i1.1427

South Africa Department of Basic Education. (2010). Education for All country report: South Africa. https://www.education.gov.za

South Africa. Department of Higher Education and Training. (2019). Post-school education and training monitor. Pretoria.

South Africa. Statistics South Africa. (2021). Statistical release P0302. Mid-year population estimates, 2020. http://www.statssa.gov.za/publications/P0302

Tang, H., \& Bao, Y. (2020). Social justice and K-12 teachers' effective use of OER: A cross-cultural comparison by nations. Journal of Interactive Media in Education, 2020(1), 9. https://doi.org/10.5334/jime.576

Tang, H., Lin, Y. J., \& Qian, Y. (2020). Understanding K-12 teachers' intention to adopt open educational resources: A mixed methods inquiry. British Journal of Educational Technology, 51(6), 2558-2572. https://doi.org/10.1111/bjet.12937

Tlili, A., Ofosu, S., \& Zhang, J. (2021). Pedagogical beliefs, teaching practices and use of open educational resources in the Republic of Ghana. Interactive Learning Environments, 1-13. https://doi.org/10.1080/10494820.2021.1894453

Tlili, A., Zhang, J., Papamitsiou, Z., Manske, S., Huang, R., \& Hoppe, H. U. (2021). Towards utilising emerging technologies to address the challenges of using Open Educational Resources: A vision of the future. Educational Technology Research and Development, 69(2), 515-532. https://doi.org/10.1007/s11423-021-09993-4

Todorinova, L., \& Wilkinson, Z. T. (2020). Incentivizing faculty for open educational resources (OER) adoption and open textbook authoring. Journal of Academic Librarianship, 46(6), 102220. https://doi.org/10.1016/j.acalib.2020.102220

UNESCO. (2002). Forum on the impact of open courseware for higher education in developing countries: Final report. Forum on the Impact of Open Courseware for Higher Education in Developing Countries, UNESCO, Paris, 1-3 July 2002: final report; 2002 (oerknowledgecloud.org)

Van Heerden, D., \& Goosen, L. (2020). Promoting the growth of fourth industrial revolution information communication technology students: The implications for open and distance e-learning. In Promoting inclusive growth in the Fourth Industrial Revolution (pp. 118-147). IGI Global. https://doi.org/10.4018/978-1-7998-4882-0.ch005

Van Winden, W. (2001). The end of social exclusion? On information technology policy as a key to social inclusion in large European cities. Regional Studies, 35(9), 861-877. https://doi.org/10.1080/00343400120090275

Walker, M., \& Mathebula, M. (2020). Low-income rural youth migrating to urban universities in South Africa: Opportunities and inequalities. Compare: A Journal of Comparative and International Education, 50(8), 1193-1209. https://doi.org/10.1080/03057925.2019.1587705

Weller, M. (2014). Battle for open: How openness won and why it doesn't feel like victory. Ubiquity Press. https://doi.org/10.5334/bam

\section{Copyrights}

Copyright for this article is retained by the author(s), with first publication rights granted to the journal.

This is an open-access article distributed under the terms and conditions of the Creative Commons Attribution license (http://creativecommons.org/licenses/by/4.0/). 